\section{LEI DE ACESSO À INFORMAÇÃO: NOTAS E UM BREVE EXEMPLO}

\author{
Marcelo Gruman
}

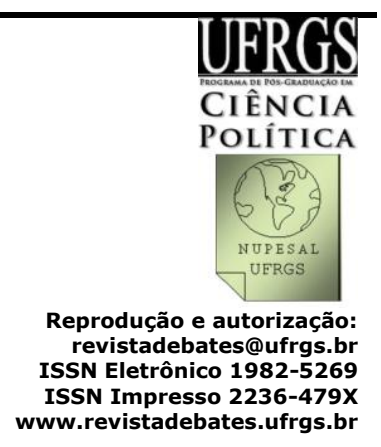

\title{
Resumo
}

O artigo analisa os principais pontos da Lei n. 12.527, conhecida como Lei de Acesso à Informação, relacionando-os a conceitos como democracia, transparência, controle social e gestão compartilhada. Argumenta-se que a consolidação da democracia no Brasil está associada a uma administração pública regida pelo princípio da eficiência nos gastos públicos a partir de políticas públicas elaboradas segundo as demandas da sociedade, e que a cultura do acesso permite cada vez mais a participação da sociedade na avaliação das ações do Estado e mesmo na proposição de mudanças de rumo.

Palavras-chave: Informações Públicas; Controle Social; Transparência; Gestão Compartilhada; Democracia.

\begin{abstract}
The article analyzes the key aspects of Law n. 12.527, best known as Information Access Law, and how they articulate with concepts such as democracy, transparency, social control and co-management. It argues that Brazilian democracy is strenghten as long as the public administration follows the principle of efficiency concerning public expenditure, and that increasing access to public information allows society to evaluate and propose direction changes.
\end{abstract}

Keywords: Public Information; Social Control; Transparency; Co-management; Democracy. 


\section{Introdução}

O estabelecimento de mecanismos de acesso à informação pública no sistema jurídico brasileiro é bastante recente. Durante a ditadura militar, o sigilo quase absoluto das ações governamentais era a regra, sob o argumento de pretensas razões de segurança nacional. Nos breves períodos democráticos anteriores ao golpe de 64, quase inexistia, mesmo internacionalmente, maior preocupação com a transparência dos atos estatais. Além disso, as características da administração patrimonialista, pré-burocráticas, portanto, eram dominantes, impedindo o nascimento de movimentos pró-transparência (LOPES, 2007). Foi apenas na reabertura democrática e, principalmente, no processo de elaboração da Constituição Federal de 1988 que o acesso à informação pública passou a ser discutido de forma mais intensa no país.

Originada nos debates travados no âmbito do Conselho de Transparência e Combate à Corrupção, órgão vinculado à Controladoria-Geral da União (CGU), discutida e votada pelo Congresso Nacional entre 2009 e 2011, no dia 18 de novembro de 2011 foi promulgada, através de publicação no Diário Oficial da União, a lei n. 12.527, mais conhecida como Lei de Acesso à Informação, dispondo sobre os procedimentos a serem observados pela União, Estados, Distrito Federal e Municípios com o fim de garantir o acesso a informações. Estão subordinados ao regime desta Lei os órgãos públicos integrantes da administração direta dos Poderes Executivo, Legislativo, incluindo as Cortes de Contas, e Judiciário e do Ministério Público; as autarquias, as fundações públicas, as empresas públicas, as sociedades de economia mista e demais entidades controladas direta ou indiretamente pela União, Estados, Distrito Federal e Municípios.

Estabelece-se o princípio de que o acesso é a regra e o sigilo a exceção, cabendo à Administração Pública atender às demandas de cidadãos e cidadãs. O acesso a estes dados, segundo cartilha elaborada pela Controladoria-Geral da União (2011, p. 8), constitui-se em um dos fundamentos para a consolidação da democracia, ao fortalecer a capacidade dos indivíduos de participar de modo efetivo da tomada de decisões que os afeta. A informação sob guarda do Estado é sempre pública, devendo o acesso a ela ser restringido apenas em casos específicos ${ }^{1}$.

A Lei de Acesso à Informação regula, em especial, o artigo $5^{\circ}$ da Constituição Federal de 1988 que, no seu inciso XXXIII, afirma o direito de todo cidadão brasileiro a receber dos órgãos públicos informações de seu interesse particular, ou de interesse geral ou coletivo "que serão prestadas no prazo da lei, sob pena de responsabilidade, ressalvadas aquelas cujo sigilo seja imprescindível à segurança da sociedade e do Estado", bem como o artigo 37, segundo o qual "toda a administração pública direta, indireta ou

\footnotetext{
${ }^{1}$ A Lei prevê exceções à regra de acesso para dados pessoais e informações classificadas por autoridades como sigilosas. Informações sob guarda do Estado que dizem respeito à intimidade, honra e imagem das pessoas, por exemplo, não são públicas (ficando protegidas por um prazo de cem anos). Elas só podem ser acessadas pelos próprios indivíduos e, por terceiros, apenas em casos excepcionais previstos na Lei.
} 
fundacional, de qualquer dos Poderes da União, do Estado, do Distrito Federal e dos Municípios obedecerá ao princípio da legalidade, impessoalidade, moralidade, publicidade e eficiência".

De acordo com o seu artigo $3^{\circ}$, os procedimentos previstos destinamse a assegurar o "direito fundamental de acesso à informação e devem ser executados em conformidade com os princípios básicos da administração pública" com as seguintes diretrizes: observância da publicidade como preceito geral e do sigilo como exceção; divulgação de informações de interesse público, independentemente de solicitações; utilização de meios de comunicação viabilizados pela tecnologia da informação; fomento ao desenvolvimento da cultura de transparência na administração pública; desenvolvimento do controle social da administração pública.

O direito de acesso à informação faz parte do debate internacional há bastante tempo, especialmente no âmbito da garantia dos direitos civis e políticos e do combate à corrupção, como atestam a Convenção das Nações Unidas contra a Corrupção em seus artigos 10 e 13

Cada Estado-parte deverá [...] tomar as medidas necessárias para aumentar a transparência em sua administração pública [...] procedimentos ou regulamentos que permitam aos membros do público em geral obter (informações) sobre a organização, funcionamento e processos decisórios de sua administração pública [...].

A Declaração Universal dos Direitos Humanos em seu artigo 19 diz que

Todo ser humano tem direito à liberdade de opinião e expressão; este direito inclui a liberdade de, sem interferência, ter opiniões e de procurar, receber e transmitir informações e idéias por quaisquer meios e independentemente de fronteiras.

A Declaração Interamericana de Princípios de Liberdade de Expressão em seu item 4, "O acesso à informação mantida pelo Estado constitui um direito fundamental de todo indivíduo. Os Estados têm obrigações de garantir o pleno exercício desse direito" e o Pacto Internacional dos Direitos Civis e Políticos em seu artigo 19 "Toda pessoa terá direito à liberdade de expressão; esse direito incluirá a liberdade de procurar, receber e difundir informações e idéias de qualquer natureza $[\ldots] "$.

A reflexão que se segue pretende apontar alguns desdobramentos da Lei de Acesso à Informação para a consolidação da democracia no Brasil, a transparência e controle social das ações da administração pública, o estabelecimento de novas formas de gerir a coisa pública em parceria com a sociedade civil e, finalmente, algumas sugestões para a produção de informações relevantes para a avaliação de uma das ações das políticas públicas de cultura, voltada para o fomento da atividade teatral. Trata-se, 
portanto, de discutir, mais amplamente, a elaboração de políticas públicas e, a partir de um breve exemplo, aquelas voltadas às artes.

\section{Acesso à informação: assimetria, simetria, democracia}

Nos dias de hoje, espaço público está relacionado ao lugar da coletividade, onde se processam os temas relativos à vida em comum dos cidadãos. Assim, espaço público é tanto o espaço físico comum, a rua, a praça, a cidade, como também as instituições através das quais uma sociedade pensa sobre si mesma e encaminha soluções aos seus problemas, o espaço da cidadania. Há muitos exemplos de temas que eram considerados privados e hoje são tratados no espaço público, gerando debates mais ou menos acalorados de grupos favoráveis e contrários à sua incorporação na agenda política. Apenas como exemplo, podemos citar os temas da liberdade de orientação sexual, da liberdade religiosa, da violência contra a mulher e contra as crianças.

Mas o fato de um tema "entrar" no espaço público, entrar na agenda política, não significa que medidas serão tomadas para resolvê-lo. Às vezes um tema entra no espaço público, é reconhecido como um problema da coletividade, mas medidas não são tomadas. Da mesma forma, não são só as leis que garantem que um problema seja suficientemente tratado. Para a maioria dos problemas, são necessárias políticas públicas que dêem conta de tratar um determinado problema. As políticas públicas são um fluxo de decisões públicas, orientado a manter o equilíbrio social ou a introduzir desequilíbrios destinados a modificar essa realidade. Decisões que são condicionadas pelo próprio fluxo e pelas reações e modificações que elas provocam no tecido social, bem como pelos valores, ideais e visões dos que adotam ou influem na decisão.

É possível considerar as políticas públicas como estratégias que apontam a diversos fins, todos eles de alguma forma desejados pelos diversos grupos que participam do processo decisório. A finalidade última de tal dinâmica constitui o elemento orientador geral das inúmeras ações que compõem uma determinada política. As políticas públicas sempre respondem a uma dada orientação e essa orientação vai influenciar as escolhas feitas para seu funcionamento.

Assim, o espaço público é também o espaço de tratamento dos temas e problemas considerados relevantes pela sociedade e a abrangência desse tratamento através de políticas públicas vai depender do quanto ele é considerado relevante. Muitos temas "entram" no espaço público e se transformam em políticas públicas a partir da reivindicação da sociedade civil, através dos movimentos sociais, daí a importância da participação dos cidadãos. Sempre haverá o risco desses interesses sociais se transformarem em mais um "cliente" do orçamento público, por meio das políticas governamentais, quando eles próprios se tornam objeto de tais políticas. 0 que importa aqui, no entanto, 


\begin{abstract}
É perceber que os atores governamentais estão expostos cada vez mais a variadas frentes de negociação quando se trata de executar aquilo que [...] constitui um dos principais resultados de sua ação, que são precisamente as políticas públicas (SANTOS, 2005, p. 6).
\end{abstract}

Percebe-se, portanto, que a transformação de um tema da agenda política em política pública, com desdobramentos objetivos, com mudanças da realidade sócio-política, depende sobremaneira do acesso à informação por parte dos grupos interessados, seja a favor ou contra a causa em questão. $\mathrm{Na}$ administração pública, a assimetria de informação é a diferença de conhecimento das ações governamentais entre os agentes do Estado e a população, que precisa ser progressivamente superada para poder tornar visível o que está oculto nas ações governamentais.

Se, conforme afirma Abramo (2006), informação é poder, e poder se disputa, numa sociedade verdadeiramente democrática deve existir livre fluxo de idéias em que grupos exerçam sua maior ou menor capacidade de convencimento e de construção de consensos. O cidadão, neste contexto, é mais do que um "confirmador da democracia" (LOPES, 2007) por meio do único instrumento do voto, um membro de grupo(s) de interesse(s), exercendo legitimamente sua cidadania num ambiente de efetiva "poliarquia".

\title{
Acesso à informação: transparência e controle social
}

A transparência, entendida como produção e divulgação sistemática de informações, constitui um dos fundamentos da chamada boa governança, entendida como a capacidade de um governo de elaborar e implantar políticas públicas, cumprindo a função de aproximar o Estado da sociedade, bem como ampliando o nível de acesso do cidadão às informações sobre a gestão pública (CULAU e FORTIS, 2006). Os governantes, ao estarem obrigados a prestar contas de sua gestão, submetem o seu desempenho à avaliação da sociedade. Ao submeterem seu desempenho à avaliação da sociedade, os gestores públicos submetem-se ao controle social, entendida, conforme a cartilha da CGU, anteriormente citada, como a participação do cidadão na gestão pública, na fiscalização, no monitoramento e no controle da Administração Pública. Este controle social é um complemento indispensável ao controle institucional realizado pelos órgãos que fiscalizam os recursos públicos.

A Lei de Acesso à Informação é explícita quanto à divulgação de informações de interesse do cidadão, dentre elas, segundo o inciso VII do artigo 70, as relativas à "implementação, acompanhamento e resultados dos programas, projetos e ações dos órgãos e entidades públicas, bem como metas e indicadores propostos". Também estabelece, através do artigo $8^{\circ}$, um papel ativo do Estado uma vez passa a ser dever dos órgãos e entidades públicas promover, "independentemente de requerimentos, a divulgação em local de fácil acesso, no âmbito de suas competências, de informações de interesse coletivo ou geral por eles produzidas ou custodiadas", obrigados a 
manter atualizadas as informações disponíveis para acesso. Passamos de uma "transparência passiva", onde a Administração Pública divulga informações sob demanda em atendimento às solicitações da sociedade, para uma "transparência ativa", em que a Administração Pública divulga informações à sociedade por iniciativa própria, de forma espontânea, independente de qualquer solicitação.

A cultura do acesso faz surgir um novo ator político, o "cidadão-fiscal" (CULAU e FORTIS, 2006) ou o "auditor independente informal" (LOPES, 2007), importante no processo de fiscalização da utilização responsável dos recursos públicos. Nos casos em que há informação suficiente, é possível analisar criticamente os números apresentados pelo governo e a metodologia utilizada para a elaboração dos dados divulgados, essencial para a mensuração do resultado de políticas públicas. Isto porque há, sempre, o risco de o governo utilizar metodologias questionáveis com o objetivo de superdimensionar os resultados de suas políticas públicas.

Sempre é bom lembrar que a manipulação de dados divulgados por governos com o intuito de fazer com que seus resultados pareçam melhores do que realmente são é algo bastante comum em democracias, mesmos nas mais consolidadas. Metodologia, forma de divulgação, base de comparação, apresentação de informações, enfim, uma série de fatores pode ser utilizada para a maquiagem de dados oficiais (LOPES, 2007, p. 23).

É claro que não se pode duvidar, a priori, sob pena de deslegitimar o processo democrático, das motivações dos agentes públicos na elaboração e divulgação de informações relativas a ações e programas governamentais. 0 que se coloca é que, quanto maior o controle da sociedade sobre as ações do Estado, menos a sociedade corre o risco de submeter-se a interesses particulares. Concordando com Abramo (2006), é lícito afirmarmos que o acesso público à informação permite um monitoramento mais atento das motivações privadas e políticas que, por vezes, interferem com as decisões técnicas. Portanto, se os grupos interessados conhecem melhor os dados administrados pelo Estado, mais difícil é o abuso de poder e a prática do clientelismo político.

A transparência das informações está diretamente relacionada ao aprimoramento dos mecanismos de alocação de verbas públicas e a qualidade dos gastos governamentais. Ao dotar a sociedade de informações públicas, o Estado permite um escrutínio das premissas adotadas para a elaboração e implantação da política pública analisada naquele momento, algo impensável em sociedades nas quais a assimetria de informação é a regra, e não a exceção, como se pretende na sociedade brasileira.

Não há como garantir que os recursos serão mais bem aplicados a partir do compartilhamento de informação, contudo, é praticamente inevitável que quanto mais incompleta ela for, maior a probabilidade de prejuízo de eficiência na alocação dos recursos. Concordando com Abramo (2006), o 
melhor argumento que os governantes podem usar ao justificar a transparência de suas ações não é o fato de ser "politicamente correto", mas porque melhora a eficiência de sua gestão.

\section{Acesso à informação: gestão compartilhada}

Prover o cidadão de informações públicas é necessário, mas não suficiente, devendo o Estado estimulá-lo à participação ativa na tomada de decisões e na formulação de políticas, incluindo a própria construção da informação pública. Trata-se, portanto, de estabelecer um diálogo com a sociedade civil numa nova maneira de gerir a coisa pública, o que se chama de gestão compartilhada.

Gestão compartilhada é a gestão realizada em conjunto por vários entes, que se reúnem para gerir um projeto, política ou programa público em busca de um objetivo comum. E o diferencial é a participação da sociedade civil. A idéia de gestão compartilhada decorre de problemas identificados na administração de políticas e programas públicos, e visa a ser um instrumento para a construção de um espaço público democrático.

A gestão compartilhada surge a partir das dificuldades enfrentadas para gerir programas e políticas que envolvem várias áreas. Por exemplo, uma política de atenção à criança e ao adolescente precisa, na maioria das vezes, envolver as áreas de saúde, assistência, justiça, contudo, as áreas não têm tradição de trabalho conjunto. Embora seja a melhor forma de enfrentar problemas complexos, as localidades não fazem mais uso desse recurso porque para os gestores, sejam eles prefeitos, secretários, diretores, muitas vezes a solução centralizada é mais fácil.

Por outro lado, o que estimula sua adoção são os princípios nos quais ela se baseia, como democracia, cidadania e participação, favorecendo também o pluralismo, na medida em que permite que várias posições sejam consideradas na condução de uma política ou programa público. No lugar de uma relação em que o governo provê o cidadão com as informações que julga pertinentes, a gestão compartilhada parte do princípio da "relação bidirecional" (LOPES, 2007), baseada no princípio da parceria.

O fortalecimento dos espaços deliberativos, como os Conselhos Gestores e, no caso específico do Ministério da Cultura, dos Colegiados Setoriais e das discussões públicas a respeito da reforma da Lei Rouanet e da Lei de Direitos Autorais, têm sido peça fundamental para a consolidação de uma gestão democrática, integrada e compartilhada. A ampliação desses espaços de participação cidadã promove um avanço qualitativo na capacidade de representação dos interesses e na qualidade e equidade da resposta pública às demandas sociais ao incorporar outros níveis de poder além do Estado.

As mudanças em curso representam uma possibilidade efetiva de transformação da lógica de gestão da administração pública, abrindo um espaço de interlocução muito mais complexo e ampliando o grau de responsabilidade de segmentos que sempre tiveram participação assimétrica 
na gestão da coisa pública. Este novo modelo, que pode ser chamado de "administração pública societal", caracteriza-se pela abertura das instituições políticas à participação social e à construção de canais de participação popular.

Essas experiências colocam em questão a tradicional
prerrogativa do executivo estatal de monopolizar a
formulação e controle das políticas públicas; permitem a
inclusão dos setores marginalizados na deliberação a respeito
do interesse público; e possibilitam que os diferentes
interesses presentes na sociedade sejam explicitados e
negociados num espaço público transparente. Em síntese,
procuram contribuir para a construção de uma cultura política
democrática nas relações entre o Estado e a sociedade
combinando ação e estrutura, política e técnica (PAES DE
PAULA, 2005, p. 44).

\section{Acesso à informação: fim ou meio?}

A finalidade principal da transparência só pode ser alcançada mediante a conversão da informação em instrumento de ação do cidadão, o que nem sempre é algo fácil de alcançar. As duas principais dificuldades estão associadas à baixa escolarização da população brasileira, especialmente a "alfabetização digital", e ao "hermetismo da linguagem técnica" (CULAU e FORTIS, 2006), daí a necessidade de utilização de uma "linguagem cidadã", segundo a Cartilha elaborada pela CGU, garantindo a leitura fácil de informações e dados. Nesta "cultura do acesso", a informação compreensível pertence ao cidadão e, a partir delas, as demandas sociais podem e devem ser atendidas.

Portanto, o acesso público à informação, ainda que primordial para a garantia de um Estado transparente e responsável, é instrumental no sentido de que os ganhos advindos das políticas de transparência governamental não se encerram em si mesmos, mas nos resultados trazidos por este tipo de política para a administração pública. A transparência e o acesso não garantem a eficácia do funcionamento da máquina pública, mas, pelo contrário, sua ausência, é garantia de mau uso dos recursos públicos porque livres de controle social. O acesso à informação é um instrumento, um meio para se alcançar um fim, a eficácia das políticas públicas.

\section{Acesso à informação: políticas para o teatro}

Em 2005, as Câmaras Setoriais foram implantadas no âmbito do Conselho Nacional de Política Cultural (CNPC) para serem espaços permanentes de diálogo entre Estado, sociedade e iniciativa privada na elaboração e pactuação de políticas públicas e diretrizes para o Plano Nacional de Cultura. As mesmas diretrizes são esperadas nos Colegiados Setoriais, substitutos das Câmaras Setoriais como órgão integrante do CNPC. 
No dia 29 de novembro de 2010, o Colegiado Setorial de Teatro publicou seu Plano Setorial de Teatro ${ }^{2}$, antecipando-se à própria Lei de Acesso à Informação no que se refere à necessidade de acompanhamento das ações do Estado no âmbito das políticas públicas voltadas ao teatro. Chama a atenção, por exemplo, o item 4.2 e o subitem 4.2.2 do Capítulo IV - Do Desenvolvimento Sustentável:

4.2: Promover o levantamento e avaliação dos dados estatísticos do setor teatral

4.2.2: Ampliar e atualizar o sistema de acompanhamento das informações e dados relativos às ações, editais e recursos econômicos da área cultural, de forma a garantir a transparência e o acompanhamento dos processos em curso.

No capítulo V - Da Participação Social, cujas diretrizes são estimular a organização de instâncias consultivas; construir mecanismos de participação da sociedade civil; e ampliar o diálogo com os agentes culturais e criadores, duas ações estão relacionados diretamente com a discussão proposta neste artigo a respeito do acesso à informação e transparência da gestão pública. São eles:

5.1: Criar canais de consulta, crítica e sugestões para acompanhamento e participação da sociedade nas políticas públicas de cultura

5.2: Fortalecer instâncias consultivas e de participação direta para o acompanhamento e avaliação das políticas públicas para o setor teatral.

Com relação à parte do item 4.2.2 que fala em ampliar e atualizar o sistema de acompanhamento das informações e dados relativos às ações, editais, é válido exemplificarmos esta ação com o Edital Prêmio de Teatro Myriam Muniz, criado em 2006, gerido pela Fundação Nacional de Artes Funarte, autarquia vinculada ao Ministério da Cultura. No relatório de atividades da instituição relativo ao ano de 2007 destaca-se o papel da unidade na execução das políticas públicas de cultura nas suas áreas de atuação. No tocante especificamente ao campo teatral, é diretriz institucional ampliar o público e valorizar a inovação e a diversidade da produção teatral brasileira.

A exemplo das demais linguagens artísticas, o teatro requer uma política de financiamento que suporte 0 desenvolvimento, a produção e a circulação de suas obras. Por conta de sua natureza de espetáculo vivo, dependente da interação de elementos cênicos e da presença simultânea e

\footnotetext{
${ }^{2} \mathrm{O}$ Plano Setorial de Teatro está disponível em <http://www.cultura.gov.br/cnpc/wpcontent/uploads/2011/07/plano-setorial-de-teatro.pdf>.
} 
física do público, trata-se de uma modalidade de expressão artística irredutível à reprodução em escala pela indústria cultural. Nesse contexto, o teatro carece de oportunidades de autonomia financeira equivalentes às cadeias produtivas do audiovisual, música popular ou literatura. Esse panorama se agrava por conta das disparidades regionais na oferta de infraestrutura de apoio à produção e fruição teatral, bem como pela distribuição irregular dos meios de capacitação de atores e técnicos e de formação de público. Entre os principais desafios estão a necessidade de apoio à pesquisa e produção dramatúrgica e cênica, revitalização dos circuitos nacionais e regionais e construção de espaços culturais que promovam a circulação e o acesso das diversas expressões teatrais existentes no país (FUNARTE, 2007, p. 10, grifos meus).

A aplicação da Lei de Acesso à Informação, no caso do fomento à atividade teatral no Brasil a partir do conceito de "transparência ativa", depende do levantamento de algumas informações, dentre as quais, sugerimos: total de proponentes inscritos; proponentes inscritos por região do país; proponentes inscritos por estado da federação, dentro de cada região do país; total de municípios com proponentes inscritos em relação ao total de municípios brasileiros com grupos de teatro (dados da MUNIC/IBGE); municípios com proponentes inscritos por região do país; municípios com proponentes inscritos por estado da federação, dentro de cada região do país; relação entre projetos inscritos nas capitais e projetos inscritos no interior do estado.

\section{Considerações finais}

Tão ou mais grave que a má utilização da informação em benefício próprio, ainda que concordemos que informação é poder, e que a disputa pelo poder faz parte do jogo político, é a omissão de informações que devem ser públicas. A omissão pode ser deliberada ou involuntária. Se involuntária, a instituição responsável pela gestão do projeto ou programa tem a obrigação de estabelecer uma política interna que dê conta da demanda externa, qualificando tecnicamente seu corpo de funcionários, ou parte dele.

Deve-se frisar, mais uma vez, a importância de combater a "maquiagem" dos dados oficiais. A "maquiagem" não significa, necessariamente, divulgação de informações falsas, mas a sua má qualidade enquanto instrumento de avaliação da política institucional, elaborada para cumprimento de suas diretrizes. De que adianta, por exemplo, divulgar aumento nas verbas destinadas a este ou aquele edital sem que haja a avaliação do seu real alcance? Como reelaborar um determinado edital sem uma avaliação de edições passadas, como planejar o futuro sem conhecimento do passado, como planejar o futuro vivendo um presente contínuo? 
Gestores públicos cientes de suas responsabilidades devem concordar que a informação pública não deve ser produzida pela área de comunicação, sob o risco de transformá-las em puro marketing, alheias à realidade, exatamente o posto do preconizado por uma administração pública cada vez mais voltada para a eficiência e a responsabilidade pelos recursos públicos.

Marcelo Gruman é Antropólogo, Doutor em Antropologia Social (PPGAS/MN/UFRJ). Especialista em Gestão de Políticas Públicas de Cultura (UnB). Atualmente é administrador cultural da Fundação Nacional de Artes.

E-mail: marcelogruman@gmail.com

\section{Referências}

ABRAMO, Cláudio Weber. Acesso à informação e eficiência do Estado. Revista do Governo de São Paulo, São Paulo, n. 2, 2006. Disponível em: <http://www.transparencia.org.br/>. Acesso em: 15 out. 2012.

BRASIL. Presidência da Republica. Lei n. 12.527, de 18 de novembro de 2011. Regula o acesso à informação inciso II do § $3^{\circ}$ do art. 37 e no $\S 2^{\circ}$ do art. Disponível em: <http://www.planalto.gov.br/ccivil_03/_ato20112014/2011/lei/l12527.htm>. Acesso em: 10 out. 2011.

CONTROLADORIA-GERAL DA UNIÃO. Acesso à informação pública: uma introdução à Lei n. 12.527, de 18 de novembro de 2011, Brasília: Imprensa Nacional, 2011.

CONVENÇÃO das Nações Unidas contra a Corrupção. Disponível em: <http://www.unodc.org/pdf/brazil/ConvONUcorrup_port.pdf.>. Acesso em: 16. out. 2012.

CULAU, Ariosto Antunes; FORTIS, Martin Francisco. Transparência e controle social na administração pública brasileira: avaliação das principais inovações introduzidas pela Lei de Responsabilidade Fiscal. In: Congreso Internacional del CLAD sobre la Reforma del Estado y de la Administración Pública, 11. Cidade da Guatemala, 2006.

DECLARAÇÃO Interamericana de princípios de liberdade de expressão. Disponível em: <http://www.cidh.oas.org/basicos/portugues/s.Convencao.Li bertade.de.Expressao.htm>. Acesso em: 16. out. 2012.

DECLARAÇÃO Universal dos Direitos Humanos. Disponível em: <http://unicrio.org.br/img/DeclU_D_HumanosVersoInternet.pdf > Acesso em: 15 out. de 2012. 
FUNARTE. Relatório de Atividades 2007. 2007. Disponível em: <http://www.funarte.gov.br/wpcontent/uploads/2010/11/RelatGestFunarte20 07.pdf. >. Acesso em: 15 out. de 2012.

LOPES, Cristiano Alencar. Acesso à informação pública para a melhoria da qualidade dos gastos públicos - literatura, evidências empíricas e o caso brasileiro. Caderno de Finanças Públicas, Brasília, n. 8, p. 5-40, dez. 2007.

PACTO Internacional dos direitos Civis e Políticos. Disponível em: < http://portal.mj.gov.br/sedh/ct/legis_intern/pacto_dir_politicos.htm>. Acesso em: 16. out. 2012.

PAES DE PAULA, Ana Paula. Administração pública brasileira entre 0 gerencialismo e a gestão social. RAE - Revista de Administração de Empresas, São Paulo, v. 45, n. 1, p. 36-49, jan.-mar. 2005.

SANTOS, Hermílio. Apresentação: políticas públicas, Estado e sociedade. Revista Civitas, Porto Alegre, v. 5, n. 1, p. 5-9, jan.-jul. 2005.

Texto recebido em 17/10/2012.

Aprovado em 12/11/2012. 